\title{
An Interview with K. M. Sherrif
}

OBED EBENEZER .S

K. M. Sherrif (hereafter KMS) is an Associate Professor and Head, Department of English, University of Calicut, Kerala. $\mathrm{He}$ is an academic, and a practicing translator who has translated into Malayalam, English, Hindi, Gujarati, and Tamil. Among his better-known works are Ekalavyas with Thumbs, the first English translation of Gujarati Dalit writing, and "Kunhupaathumma's Tryst with Destiny", the first study of Vaikom Muhammed Basheer's fiction in English.

Obed Ebenezer .S (hereafter OE) is a Research Scholar at the Department of English, University of Calicut. He is currently doing his Ph.D. in Translation, Cognition, and Poetry. He is a freelance translator and mostly translates from Malayalam to English.

OE: The traditional view of the translator as a traitor, popularised by the Italian phrase- "Traduttore, traditore", has opened up Pandora's box of questions and assumptions, not the least of which, are the notions of originality, authorship, copyright, etc. Do you feel a change in how the translator and the process of translation are being viewed today?

KMS: The days of the traitors are gone! The paradigm shift that happened in Translation Studies in the Eighties of the Twentieth Century altered the landscape of translation. Translators who had been labelled traitors were absolved. Translation came to be looked upon as a form of rewriting. The notion that translators rewrote texts to conform to the aesthetics and ideologies of the target culture, or the ideologies and aesthetics they profess, began to be widely recognized. This would naturally mean that translators are authors in their own rights. At this point, the binary of the source text rewriting was still acknowledged and the source text was still privileged 
as the original 'point of enunciation'. A little later, when Adaptation Studies emerged as a discipline, it was pointed out that a rewriting/adaptation could diverge so much from the antecedent text that it would merely serve as a launching pad for the rewriting/adaptation. I think it can be safely said that the notion of originality is a badly skewed one. All texts have intertextual relationships with texts that arrived before them. Thomas Leitch would talk about texts floating in a sea of intertextuality! Of course, the intertextuality may not be clearly evident, except when the rewriting relies largely on one single text. I say largely, because even in what appears a straightforward translation, other texts would be implicated. Although literary theory has accorded the status of authors to translators (the charter on translation published by PEN clearly says so), copyright laws still privilege the 'original' author. Translation scholars do not make copyright laws!

OE: The Man Booker International Prize, from 2005 until 2015, was given every two years to a living author of any nationality for a body of work published in English or generally available in English translation. However, since 2016, the award has been given annually to a single book in English translation, with the prize and the winning title shared equally between the author and the translator. This is evidence of the changing perception of the translator. But, in your opinion, and your experience, how far has this change of perception been seen in practice, at least concerning the Indian scenario?

KMS: I do not think it has taken off in that manner in India. Of course, translators are more recognized today than they were before. The Sahitya Akademi gives awards for translators every year. There are awards for translators given every year by academic bodies and publishers in many languages in India. But an award like Man Booker which recognizes both the 
author and the translator is yet to materialize. However, the JCB Awards for Indian fiction in English or Indian fiction translated into English have gone part of the way, in offering a smaller amount as a prize to the translator too in the case of the latter. But, both in academia and in the popular imagination, the translator is still at best a secondary author.

OE: The translator has always been mostly "invisible", to use Lawrence Venuti's term. However, there have been instances where writers such as Seamus Heaney and Ted Hughes, have purposefully engaged in translating lesser-known works, to bring them to a wider audience. How do you view this? And what has been your experience in this matter?

KMS: Translators who have established themselves as writers are different. They are often larger-than-life presences even in translation, Ezra Pound being the classical case. Their visibility as writers plays a big role in the process of canonization through translation. Their authority as writers often canonizes the author, who may not be part of the canon of the source culture. For my part, although I do not have the 'literary authority' of translators like Ezra Pound, I have been instrumental in bringing several poets and writers in Malayalam, who were not known outside Kerala, to the notice of readers of Indian writing in English. I have also tried my hand at translating the occasional striking poem I find on social media into English. Some of them have not been published in print.

OE: What is your take on the view that translation is resistance?

KMS: Like all forms of writing and rewriting translation can take the form of resistance. The role of translation in political action has been fairly well documented. The very act of translating a text whose entry into the target culture is prohibited by law may constitute resistance. Translation can 
gather public support from outside for an author persecuted in his society. Campaigns to end the persecution of beleaguered writers and to restore their human rights are often triggered by the translation of their works. This has happened to hundreds of writers in the last century.

OE: This naturally, brings up the issue of Dalit Literature in Translation. You have translated Dalit writings from Gujarati, Malayalam, Tamil, and Hindi, into English. What are the common characteristics and the major differences you have noticed while translating them? Dalit writing in these languages is available in English translation. But translation between these languages appears to be not so visible. Is the colonial legacy still at work? Is there a point in insisting that the subaltern should speak in translation too, that Dalit writing should be translated by Dalit writers?

KMS: Dalit writing appeared as a mode in these languages at different times. Among these languages, Gujarati was the first to record the presence of a Dalit literary movement. That happened in the Seventies of the last century. Of course, there were works, which represented Dalit issues from a Dalit perspective even before that. But they had not acquired the identity of a Dalit movement. In the other three languages, an identifiable movement of Dalit writing appeared only towards the end of the century. One can identify many similarities and differences. There are big differences in the use of dialects, in the themes, in the ways in which social stratification is represented. Yet Dalit writings in all the four languages have turned political, seeking to overhaul both the aesthetic and ideological paradigms of their 'mainstream' writings.

The market seems to have played a decisive role in promoting translations into English. There is always a wider audience for translations into English. And there are more translators available for translation into English than for translation 
between these languages. But translation between these languages, as between other languages in general, is certainly looking up. The transactions between Gujarati and Marathi, and between Tamil and Malayalam, have been quite lively for the last several decades, which is quite natural, considering they are geographically contiguous languages. But writers like Sharankumar Limbale and Omprakash Valmiki are now also available in Malayalam and Tamil.

It is pointless to wrangle about whether Dalit writers should ideally translate Dalit writing, just as it is to insist that Dalit writers should write about Dalits. But it should not be forgotten that a Dalit translator is in a better position to understand the subtleties and nuances of Dalit writing. But this should not be foisted as a dogma. Talal Asad has sounded a note of caution when he remarked that in anthropological writing an indigenous writer's accounts need not necessarily be authentic or accurate.

OE: Translation Studies as an academic discipline came into existence with James Holmes' proposal in his paper "The name and nature of translation studies" in 1972. However, studies and treaties on translation have existed before it. Do you think that Translation Studies need to be treated as a different discipline, or should it continue to remain under the umbrella of Linguistics, and Literature? Isn't translation, after all, an exercise in language and culture? What is your take on this?

KMS: Holmes was trying to 'give a name and a local habitation' to translation studies. But translation or translation studies were not airy nothings before that. Translations from Greek were of great academic value in the Roman Empire. There were some discussions on the objectives and methodology. In China, as we learn from the translation scholar, Wei Zhong, there were discussions on literal versus 
free translation- a core issue in translation even today- during the period from the Third Century BCE to the Third Century $\mathrm{CE}$, in the context of translations of Buddhist scriptures from Sanskrit to Chinese.

Translation Studies formally left its home in linguistics and literature in 1983, when the Modern Languages Association gave a separate entry for Translation Studies in its bibliographies. But things happened rapidly after that. In the same decade the Translation-Culture School of Translation Studies, with scholars like Andre Lefevere, Susan Bassnett, Mary Snell-Hornby, and Theo Hermans in the vanguard, subverted and overhauled the traditional paradigms of translation theory. Translation began to be accepted as a form of cultural rewriting. Not long after that, at the turn of the century, Adaptation Studies emerged as a discipline, which engaged all forms of cultural rewriting across media, genres, and modes. Translation Studies has virtually become one of its branches.

OE: Moving to the academic side of Translation, do you hold the view that Translation must be introduced as a taught course at colleges and universities, at least at the Post-Graduate level? What is the need, and how can it be implemented?

KMS: Yes, of course. Translation is one of the most prolific human activities. I have remarked that all human beings are translators. Even monolinguals are doing it all the time translating between registers and levels, and sometimes among dialects. A certain amount of prescriptiveness remains in Translation Studies programmes, which is inevitable, considering they are often meant for prospective translators. Translators are in great demand in technologically advanced multilingual societies. The European Union makes all its documents available in 27 languages. Ideally, a Translation Studies programme should be largely descriptive in nature, 
analysing available translations, and using theory to understand the process of translation and to resolve particular issues.

OE: There have been several 'trends' or 'turns' in Translation Studies. Translation took on a 'linguistic turn' in the 1920s with Jakobson, Nida, Sapir, and Whorf. It took on a 'cultural' turn in the 1980s. It then became 'interdisciplinary' in the 1990 s, with a 'postcolonial' turn in 1988, then into 'gender', and now there is a 'sociological' trend and 'cognitive turn'. Does the translator, in practice, concern himself/herself with these issues? Or, do these issues arise from different readings and interpretations?

KMS: Many translators go to town with little or no theoretical moorings. This is not all that bad, considering that translators learn more from contemporary practice and literary 'attitudes' but theoretical insights do help translators in their job. Way back in the Third Century BCE, the Chinese Emperor who commissioned the translation of Buddhist scriptures from Sanskrit to Chinese also appointed a translation bureau chief: an Indian, who supervised the translations, armed with the theory that scriptures called for close translation. There are translators who have gone on to become translation scholars. The American translation scholar Lawrence Venuti is also a translator who has applied translation theory to his translations between Italian and English while arriving at many of his theoretical formulations from his translation practice.

OE: With respect to the cultural turn of the 1980s, there has been a shift in the notion of translation. Andre Lefevere developed the idea of translation as a form of rewriting, influenced by ideologies and poetics/aesthetics. What has been your experience with regard to this?

KMS: As a practicing translator you can call me an ardent devotee of the Rewriting-Culture School of Translation Studies 
in the West! I have consistently subscribed to the notion of translation as rewriting, especially in my translations of poetry. It was this conviction that made me rewrite N. N. Kakkad's poem "Pothu" (buffalo) as "Portrait of a Pig." Nearly everything was changed. The buffalo in the original became a pig. It lay, not in a muddy pond, as the buffalo had done, but near a garbage heap on the sidewalk. But Kakkad's poem, published in 1976, was intensely political, an exasperated outburst against the complacency of the leisurely class which refused to leave its safe zones during the Emergency. I thought the pig, with its typical associations for the Euro-American reader, was as good a trope as the buffalo in Kakkad's poem. During the more than three decades of my career as a translator, I have been constantly reminded of the ideological and aesthetic factors which come into play as the translator negotiates the twists and turns on the road from the source culture to the target culture.

OE: Again, ideologies and aesthetics are not the only driving forces behind rewriting. Culture has definitely become an 'industry'. Thus, the scope of translation becomes limited by the market. In short, it is the market, which decides what is to be translated, and how it should be translated. How would you respond to this?

KMS: Well, you cannot keep the market out of anything these days! The market is primarily interested in bestsellers. As for the method of translation, publishing houses would go for domesticating translation all the time. Domesticating translations are readerly translations that read smoothly, almost like a text originally written in the target language. You do not have to grapple with it as you have to with a writerly text or a foreignizing translation. Even Nobel laureates may not make the grade if they cannot sell. But in working against the ideology of the market, one finds not only the traditional 
academia with its clichéd rejection of 'filthy lucre', but also politically committed (one way or the other) translators who use crowd-funding to publish their translations and use cyberspace to take their translations in digital form to large numbers of readers. Publishing on the Internet is a prolific activity today.

OE: If, as you described it, Adaptation Studies is an 'umbrella discipline' to Translation Studies, how exactly do you describe it as engaging with rewriting of texts?

KMS: As a discipline, Adaptation Studies is, perhaps, too allencompassing. It is a hold-all in which rewritings in any cultural phenomenon can be discussed. But its apparent unwieldiness is not all that bad. There is probably a certain unity underlying all cultural phenomena including rewriting, just as there are natural laws that bind all physical and chemical processes in the universe. Lefevere was, I think, saying as much when he tried to explain that translation as rewriting is governed fundamentally by ideology and aesthetics. One can divide Adaptation Studies into convenient sub-categories like adaptation in literature, adaptation in cinema, adaptation in music, etc.

OE: How do you look at 'originality' and 'intertextuality', two terms which have acquired new significance after the advent of the Translation-Culture school of Translation Studies?

KMS: 'Originality' is a term that is bandied about conveniently. When applied to texts, the term is deceptive in two ways. For one, every text is something new, original. What is the point of a 'faithful' reproduction? Who will read it/listen to it/watch it, if it has all been read/heard/seen before? On the other hand, no text can completely exclude the texts that have come before it. Influences, unconscious borrowing, close imitation - many of these are for everybody to see. There are also texts whose antecedent texts have been 
discovered later. It was believed that Cinthios's story in Italian "A Moorish Captain" (Un Capitano Moro) was the 'original' source for Shakespeare's Othello till the English translation of The Arabian Nights revealed that there was a story in Arabic with almost the same plot which Cinthio was likely to have borrowed for his story. Karl Marx famously said that the history of human society is the history of class struggles. The history of literature/art is the history of intertextuality. Borrowing, adapting, rendering, remaking - rewriting happens in many ways. No text is free of intertextuality.

OE: Again, the notion of originality has given rise to copyright. However, it is a fact that copyrights are held by publishing houses rather than the author. And translation rights are required in order to publish translations. What is your opinion of this practice?

KMS: In a world tightly controlled by the market, writers and artists often have to surrender their rights to their texts to get them published. Translators have to take the rights, not from the authors, but the publishers. But copyright is a market right. The first copyright laws were passed in Britain in 1707. Printing in Europe had taken great strides by then. It had become possible to sell thousands of copies of popular books. The copyright regime as it operates in translation also reveals its capitalist origins. For instance, when all the work is done by the translator, why is it that the author is often paid half or more of the total royalty? Even with the pittance they get, translators are often reduced to the near-invisibility of the small print on the cover. There may not even be a one-sentence bio of the translator on the blurb or the inside cover. But copyright or even authorship is, interestingly, disappearing from cyberspace, especially in social media. Posts are shared with additional comments, poems are modified, authors of the more pungent (especially topical) jokes choose to remain 
anonymous. It seems we are moving towards the kind of unlimited intertextuality that existed in pre-modern times.

OE: Shifting to Poetry, you have translated a fair number of poems into English. What is it, in your opinion, that makes translation of Poetry different from that of Prose?

KMS: Although many translation scholars have given much attention to the translation of poetry (Lefevere's "Translation of Poetry: Seven Strategies and a Blueprint" comes immediately to mind), such distinctions as between poetry and prose are less important than the translator's familiarity with the genre or discourse and the 'innate' ability to navigate in it. One cannot posit a binary like poetry-prose. Translation of fiction poses as many problems as the translation of poetry. It must be noted that some of the most distinguished translators of literature are writers or poets. It can also safely be said that even those who are not, have a certain 'latent' or secondary creativity that is triggered by the source text.

OE: Recently, you have taken interest in what is called 'Knowledge Translation'. Could you elaborate on this? How is this different from other modes of translation?

KMS: I would not like to make a fundamental distinction between knowledge translation and other types of translation. But from the earliest known instances, translation of knowledge texts was a process, which was closely monitored by its patrons. The translation of Buddhist scriptures from Sanskrit to Chinese, and the translation of the Bible from Latin into various European languages during the Medieval period involved much discussion and deliberation. As it was with those texts, for the translation of modern knowledge texts, especially in the sciences and humanities, close translation is preferred. The kind of cultural relativity that influences literary translation does not work in knowledge translation. As part of its drive to make knowledge texts in English and other foreign 
languages available in Indian languages, the National Translation Mission has undertaken a massive programme of recruitment and training of translators.

OE: The recent advances in cognitive science have made it possible to map the activity of the brain process during translation. Some of the findings reveal that the brain activity of trained translators has a marked contrast as compared to untrained translators. This results in huge differences as to the time, energy, and mental activity expended. In the light of these findings, do you see any difference in how you translate today, as compared to when you first started? Do you translate faster, with lesser effort?

KMS: 'Practice makes perfect', is a dictum that operates everywhere. Translation is no exception. The findings in cognitive science only corroborate what is quite well known. The huge differences in time and energy are evident to translators who have been around for some time. It is no exaggeration to say that the mind of an accomplished translator spits out translations of portions of the source text as instantaneously as a computer. Interpreters have to do it instantaneously anyway, which is why there are rigorous training programmes for interpreters. My experience as a translator has been no different.

OE: What were the primary influences in your career as a translator? Over the years you have been involved in translating a wide range of genres. What/who would you say has impacted you most?

KMS: There are a number of good translators in Malayalam. I have certainly been influenced by the way they have made the source texts come alive in Malayalam. M. N. Sathyarthi and the Omana-Gopalakrishnan couple come to mind first. Sathyarthi, who was an associate of Bhagat Singh has translated from Bangla, Hindi, Punjabi, and Urdu. Omana and 
Gopalakrishnan, who lived in Moscow and were associated with the Progressive Publishers, translated dozens of works, including children's literature from Russian. Then there is the master author-translator V.K.N., whose Bovine Bugles (translation of his novel "Arohanam" in Malayalam) can serve as a specimen for students of translation. Malayalam literature is highly receptive to translations, a literature in which translated texts occupy, not the margins, but the centre of the polysystem.

OE: The development of the cognitive turn in translation arose primarily due to the inadequacy and the impossibility of achieving fully automatic translation. What do you think will be the future of Translation? Would Machine Translation replace humans? Or do we still have a long way to go?

KMS: I don't think machine translation will phase out human translators, at least not in the foreseeable future. Language is too complex a phenomenon to be programmed. One can think of applying machine translation to limited discourses transport and communication systems, weather forecasts, disaster management, and the like. More such limited discourses can be brought into the domain of machine translation. But the translation of literature will remain a human activity. Of course, one can think of setting up a growing database of translation memory that can be programmed to develop as translators work online.

The translators can work with the existing database while every innovation they introduce will be added to it and will appear as an option in the menu when the next translator works with the memory. Depending on what is translated and the number of translators, a stupendously large online dictionary/thesaurus which can operate at all levels from word to a sentence can be established between language pairs. One 
Obed Ebenezer .S

can dream of working with this memory and producing workable translations in, say, a hundred years' time!

$* * *$

\section{Cite This Work:}

EBEnEZER, OBED .S. 2021. An Interview with K. M. Sherrif.

Translation Today, Vol. 15(1). 221-234.

DOI:10.46623/tt/2021.15.1.in1 